\title{
Learners' Attitude to a Reformed Evaluation in CALL Context
}

\author{
Tuo Ya \\ Ethnic Education School \\ Beijing University of Posts and Telecommunications \\ PO box 306, 10 Xi Tu Cheng Street, Beijing, 100876 \\ tuoyabupt@163.com
}

\author{
Xia Zengyan \\ Ethnic Education School \\ Beijing University of Posts and Telecommunications \\ PO box 306, 10 Xi Tu Cheng Street, Beijing, 100876
}

\author{
Li Jun \\ Ethnic Education School \\ Beijing University of Posts and Telecommunications \\ PO box 306, 10 Xi Tu Cheng Street, Beijing, 100876
}

\begin{abstract}
The purpose of the paper is to introduce a reformed evaluation approach and to probe into the attitude of the students to the new evaluation system in accordance to a reformed CALL environment. A questionnaire survey is conducted in the experimental class to get a general idea of the learners' identification and acceptance degree to the new evaluation approach. The results show that the reformed evaluation approach has won acknowledgement from an increasing number of students in experimental classes. Nevertheless, further efforts have to be made to ensure the reliability and the credibility of computer-based assessment in order to improve the evaluation approach in the CALL context. In the end, the authors summarize the advantages of the reformed evaluation approach under CALL mode over the traditional one, as well as the problems of the new approach.
\end{abstract}

Keywords-Traditional evaluation, CALL-based evaluation, Formative assessment, Summative assessment

\section{INTRODUCTION}

The interest in CALL in EFL education has been proliferating internationally. College English education in China has also witnessed a significant reform. The College English Curriculum Requirements issued by Ministry of Education requires that colleges and universities should reform the existing teacher-centered foreign language teaching mode by introducing computer-based or intranet- or campusnetwork-based multimedia modes.

Our university is one of the Universities in China that have initiated CALL-based College English Education Reform. Experimental classes have been organized in each grade since 2010 to introduce CALL practice in college English classes.

We have adopted a 'blended learning' approach in Experimental classes, using a combination of computer-based and printed materials, together with classroom sessions and interviews with teachers.
As practitioners and researchers, the writers have kept track of the Experimental Classes for 3 semesters, and have already conducted surveys in the following aspects: On Learner's Acceptance of CALL Advantages and Its Correlation with Learners' Personal Backgrounds; A Comparative Study on the Expected Benefit and the Actual Benefit of CALL.

In response to the new CALL mode, we have carried out evaluation reform accordingly, in the belief that it is an integral part of EFL education reform, and can contribute greatly to the smooth running and the final success of EFL reform, and that learning, evaluation and technology are interrelated components in language learning and teaching, and that impartial and objective evaluation can help to track the learning process, and provide teachers with up-to-date status quo concerning English learning.

Conventionally, examinations have been equated with paper-based examinations organized and conducted by teachers, with the focus on reading and writing skills, and consequently leading to unbalanced development in English competence, with rather poor abilities in speaking and listening.

Now there is a demand for reforming the EFL evaluation system.

\section{OUR PRACTICE}

We have experimented with a 'Reformed Evaluation Approaches in CALL Context' in the past three semesters, with the following new features:

(1) A larger proportion is given to routine-performance assessment in the final grading. We have increased the routineperformance assessment from $20 \%$ to $40 \%$ for the purpose of enhancing the students' awareness of learning process, and guiding the teachers to attach greater importance to formative evaluation.

(2) Computer-based assessment is introduced to promote students' autonomous learning and individualized learning. 
The student's self-access performance is tracked and recorded automatically, involving study time, study material, study pace, computer-mediated interactive practice and test achievement, etc. All the information is rated in the final grading.

(3) Assessment of performance in the Interview Class is included in the final grading. Interview classes with $6 \sim 14$ students have been organized each week to create an interactive setting for oral practice. The regular classes of around 50 students are split into several smaller ones on a voluntary basis, during which the teacher will either guide the students in oral discussions on given topics, or interview the students to assess their learning of the oral material.

(4) Multi-evaluation approaches have been introduced to encourage creative and individualized learning. Students are given larger space and greater freedom to do their assignment. For instance, oral work and written work can be done in different forms, either through computer, paper, tape, or face to face. Assigned tasks are more open, more flexible, more varied, more stimulating, more co-operative, and more self-directed. Peer assessment, self-assessment and teacher assessment all play a part in the final grading.

\section{RESEARCH}

\section{A. The purpose and rationale}

As Levy (1997) put it, learners are the driving force in shaping the character of the task, creation of the electronic materials, and approach of the assessment[4]. Therefore, 'the importance of the learner's perspective must be recognized in all modern approaches to the language-learning process' [2, 3]. We are in complete agreement with Chapelle[1] in the notion that the interdependency of instruction design and evaluation can contribute substantially to the ultimate success of CALL materials in the classroom.

After one and half years' practice, we conducted a survey in the hope of getting a good knowledge of the students' perception on the reformed evaluation approach under CALL model.

\section{B. The Subjects}

The subjects are 284 sophomores (137 males and 147 females) from CALL experimental classes, who have already had 3-semester CALL experience. They are selected at random from different departments.

\section{The instruments}

All the data are processed by SPSS for Windows 13.0. 'Descriptive Statistics' and 'Compare Means' are used respectively to analyze the relationships between the variables.

\section{The collected statistics and analyses}

The following are the questions from the questionnaire and the analyses of the students' responses.

\section{Question 1}

The teacher' final grading should be based on
A) Routine performance and final examination

B) Routine performance, mid-term examination and final

C) Mid-term examination and final examination

D) Final examination

TABLE I. THE RESPONSE TO QUESTION $1(\mathrm{~N}=284)$

\begin{tabular}{|c|c|c|c|c|}
\hline & $\mathrm{A}$ & $\mathrm{B}$ & $\mathrm{C}$ & $\mathrm{D}$ \\
\hline Frequency & 158 & 99 & 7 & 20 \\
\hline Percent & $55.6 \%$ & $34.9 \%$ & $2.5 \%$ & $7.0 \%$ \\
\hline
\end{tabular}

A vast majority of the students accept the pattern that combines formative evaluation of routine performance with summative evaluation in the form of final examinations. Over $50 \%$ of the students hold that mid-term examinations are unnecessary; only the routine performance is effectively observed, recorded and rated.

\section{Question 2}

What percentage do you hope routine performance assessment accounts for in the final grading?
A) $10 \% \sim 20 \%$ B ) $30 \% \sim 40 \%$
C) $50 \% \sim 60 \%$
D) $70 \% \sim 80 \%$

TABLE II. THE RESPONSE TO QUESTION 2 (N=284)

\begin{tabular}{|l|c|c|c|c|}
\hline & A & B & C & D \\
\hline Frequency & 34 & 126 & 110 & 14 \\
\hline Percent & $12 \%$ & $44.4 \%$ & $38.7 \%$ & $4.9 \%$ \\
\hline
\end{tabular}

Most of the respondents hope that routine performance assessment takes around 30\% 60\% in the final grading, which reflects students' enhanced awareness of the learning process and practical skill development.

\section{Question 3}

In the assessment of routine performance, what percentages should the following items account for?

A)Class attendance ( \%)

B)Classroom-based performance (including oral presentation, answering questions, practice activities, etc.) ( \%)

C) Computer-based assessment of autonomous learning ( \%)

D) Performance in the Interview Class ( \%)

E) Paper work (including composition, research report, translation, etc.) ( \%)

TABLE III. THE RESPONSE TO QUESTION 3 (N=284)

\begin{tabular}{|l|c|c|l|c|l|}
\hline & A & B & C & D & E \\
\hline Mean & $21.20 \%$ & $19.79 \%$ & $14.77 \%$ & $15.13 \%$ & $29.2 \%$ \\
\hline $\begin{array}{l}\text { Std. } \\
\text { Deviation }\end{array}$ & 13.03 & 13.54 & 8.61 & 7.97 & 12.84 \\
\hline
\end{tabular}

The students give the largest percentage (29.2\%) to paper work, which focuses on reading and writing skill, while they give the lower percentages to the new assessment approaches--'Computer assessment of autonomous learning' (14.77 \%) and 'Performance in the Interview Class' (15.13 \%). The Std Deviation for 'Class attendance' (13.03), 'Classroom-based performance' (13.54) and 'Paper work' (12.84) are comparatively large, which suggests there is a great disparity 
between the students' attitudes. By further analysis, we find students' scores are positively correlated to 'Classroom-based performance' $(r=0.39$ Sig. (2-tailed) $=0.041)$; Female students give a higher percentage $(23.9 \%)$ to 'Class attendance' than their male peers (18.3\%).

\section{Question 4}

What percentage do you hope the assessments of the following skills respectively account for in the final grading?
A) Listening ( \%)
B) Speaking ( $\%)$
C) Reading ( $\%)$
D) Writing ( \%)

TABLE IV. THE RESPONSE TO QUESTION 4 (N=284)

\begin{tabular}{|c|c|c|c|c|}
\hline & A & B & C & D \\
\hline Mean & $21.8 \%$ & $16.9 \%$ & $32.2 \%$ & $29.1 \%$ \\
\hline $\begin{array}{c}\text { Std. } \\
\text { deviation }\end{array}$ & 5.76 & 7.63 & 8.33 & 5.44 \\
\hline
\end{tabular}

Many students stick to the conventional notion that reading and writing skills are prior to listening and speaking skills in evaluation, which is not an unexpected result considering the long-term reading and writing-focused evaluation. However, in spite of the low proportion given to speaking, it shows a significant increase compared with the figure (10.2\%) we collected from the questionnaire survey conducted at the beginning of the CALL Experiment. The change in the proportion indicates students' slow but steady acceptance of speaking training.

\section{Question 5}

Do you like to be assessed on computer? Why or why not?
A) Yes
B) No

TABLE V. THE RESPONSE TO QUESTION 5 ( $\mathrm{N}=284)$

\begin{tabular}{|c|c|c|}
\hline & A & B \\
\hline Frequency & 96 & 188 \\
\hline Percent & $33.9 \%$ & $66.1 \%$ \\
\hline
\end{tabular}

About two thirds of the respondents take a negative attitude to computer-based assessment. From the reasons given by the students, the following two are dominant:

1) In the course of computer-based assessment, students can neither skip what they don't want to do first, nor can they check what they have done because the software has no 'save' function.

2) During computer-mediated speaking tests, it sounds unnatural and impersonal to talk to the computer.

\section{Question 6}

Do you think computer-based assessment is reliable and credible?
A) Yes
B) No

TABLE VI. THE RESPONSE TO QUESTION 6 (N=284)

\begin{tabular}{|c|c|c|}
\hline & A & B \\
\hline Frequency & 108 & 176 \\
\hline Percent & $38 \%$ & $62 \%$ \\
\hline
\end{tabular}

Again, most students fail to acknowledge the reliability and credibility of computer-based assessment for the following reasons:

1) Owing to technical limitations, most questions, including translation, short-answer questions, conversation-making and gap-filling exercises are supplied with only one right answer, while other alternatives will be judged 'wrong' by the computer. It's biased and inflexible.

2) Cheating of different kinds, such as copying, sitting in the exam for others and plagiarizing, is hard to be detected in the computer-based assessment.

\section{Question 7}

In which of the following skills have you made the greatest progress under the new evaluation model?
A) Listening
B) Speaking
C) Reading
D) Writing

TABLE VII. THE RESPONSE TO QUESTION 7 (N=284)

\begin{tabular}{|c|c|c|c|c|}
\hline & A & B & C & D \\
\hline Frequency & 156 & 112 & 16 & 0 \\
\hline Percent & $54.9 \%$ & $39.4 \%$ & $5.6 \%$ & $0 \%$ \\
\hline
\end{tabular}

The vast majority of the respondents acknowledge the guiding role of the new evaluation model, under which they have gradually shifted from reading-and-writing-focused English learning to all-round development, with much more efforts on speaking and listening improvement. This is exactly the initial goal we set at the beginning of the CALL experiment.

\section{Question 8}

Which of the following two evaluation approaches do you prefer?

A) Traditional test-oriented evaluation approach

B) The new reformed evaluation approach under CALL model

TABLE VIII. THE RESPONSE TO QUESTION 8 (N=284)

\begin{tabular}{|c|c|c|}
\hline & A & B \\
\hline Frequency 212 & 72 & 212 \\
\hline Percent & $25.4 \%$ & $74.6 \%$ \\
\hline
\end{tabular}

Three quarters of the respondents accept the reformed evaluation approach as superior to the traditional one, which is an encouraging feedback for us. Still, there are one quarter of the respondents who show resistance to the new approach and need more time to adapt.

\section{SUMMARY}

From the survey and the follow-up discussion with some of the respondents, we conclude that the reformed evaluation approach under CALL model has shown its advantages over traditional ones in the following aspects:

1) Enabling the teacher to evaluate the performance of the learners of different learning styles and personalities in more comprehensive, and more impartial ways.

2) Effectively promoting autonomous learning and individualized learning under CALL model. 
3) Motivating learners to practice listening and speaking, and helping to overcome the prevalent problem of 'dumb English' and ‘deaf English’.

4) Encouraging creative and co-operative learning.

According to the questionnaire, problems arising from the new evaluation approach under CALL model are as follows:

1) The reliability and the credibility of computer-based assessment is now far from satisfactory.

2) Software for evaluation is inadequate both in quality and in quantity at the present stage.

3) Some learners and teachers who are used to traditional evaluation system show resistance to the new evaluation approach.

\section{REFERENCES}

[1] Carol Chapelle, Multimedia CALL: Lessons to be learned from Research on Instructed SLA [J]. Language Learning \& Technology, 2(1): 22-34, 1998.

[2] Elaine Tarone \& George Yule, Focus on the Language Learner [M]. Oxford University Press,

[3] Gardner, R. C., \& Lambert, W. E. 1972. Attitudes and Motivation in Second-Language Learning. Rowley, Mass.: Newbury House Publishers, 1996.

[4] Levy, M, Theory-driven CALL and the development process [J]. Computer Assisted Language Learning, 10:14-56, 1997. 